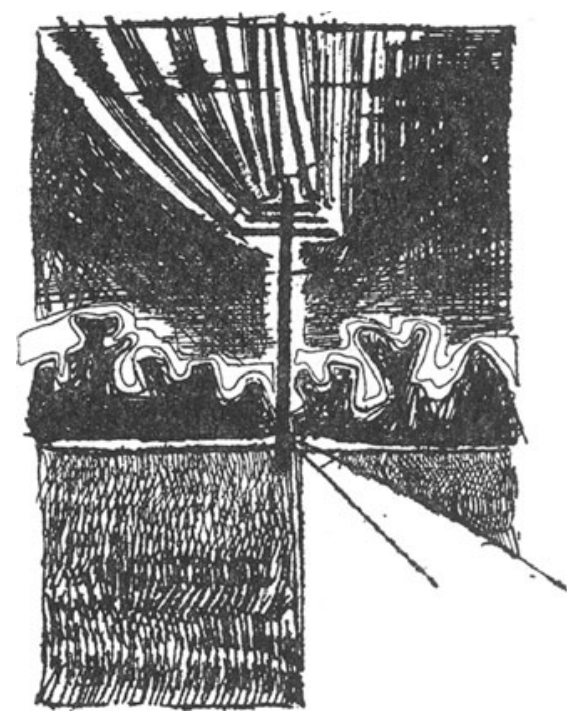

\title{
NOBODY COMES
}

Tree-Leaves labour up and down, And through them the fainting light Succumbs to the crawl of night. Outside in the road the telegraph wire To the town from the darkening land Intones to travellers like a spectral lyre Swept by a spectral hand.

A car comes up, with lamps full-glare,

That flash upon a tree:

It has nothing to do with me, And whangs along in a world of its own,

Leaving a blacker air; And mute by the gate I stand again alone, And nobody pulls up there. 